\title{
Antibiotic Impregnated Beads in Open Fractures. A Report on the Technique and Possible Applications in Military Surgery
}

\author{
Maj G W Bowyer \\ FRCS, RAMC \\ Lecturer in Military Surgery
}

\section{Chemical and Biological Defence Establishment, Porton Down, Salisbury SP4 OJQ}

SUMMARY: The use of antibiotic impregnated beads has been shown to be a valuable adjunct in the prevention of infection in open fractures. The bead pouch technique employs these beads within the wound, producing high loca疋 levels of antibiotic in a moist environment. This effectively inhibits bacterial colonisation and wound infection whilsê preventing desiccation of structures such as bone and tendons. This technique can be used to manage wounds until sof $\overrightarrow{0}$ tissue cover is obtained, whether by delayed primary suture or by plastic surgical means.

The potential use in acute military surgery includes the management of wounds associated with fractures, damage tow tendons or neuro-vascular injury. In such cases delay in soft tissue cover may be clinically necessary or dictated b용 casualty evacuation to rearward surgical facilities. The bead pouch technique offers a means of managing the wounç्仓 between initial wound surgery and soft tissue cover.

\section{Introduction}

Antibiotic impregnated beads have an established role in the treatment of osteomyelitis $(1,2,3)$, but a recent innovation has been the use of these beads for the prophylaxis of infection in open fractures $(4,5)$. In particular the "bead pouch" technique offers a method of preventing infection, whilst avoiding dessication of the wound.

This paper sets out a brief background to the technique and describes its use. Results are reviewed from open fractures treated in a United States trauma centre which employs this system.

This technique may have a role in the management of soft tissue wounds and fractures in a military surgical practice, and the potential for this is examined.

\section{Historical Background}

Antibiotic was incorporated in polymethylmethacrylate (PMMA) cement in 1970, and by 1972 was in routine use in joint replacement arthroplasty at the Hamburg Endo-Klinic (6), where it was regarded as an important part of prophylaxis against infection. In the mid-1970's this antibiotic-cement combination was made into beads, and employed in the treatment of established bone infection by Klemm (1). In 1976 gentamicin impregnated PMMA beads became commercially available in Europe (Septopal ${ }^{\circledR}$, E Merck), and have found applications in general surgical as well as orthopaedic practice $(7,8)$, mostly in the treatment of established infections. The use of beads in the prevention of infection in open fractures was an extension to their use in the treatment of osteomyelitis. Considerable work in this area has been done by Professor David Seligson's unit in Louisville, Kentucky $(4,5,9,10)$, developing the "bead pouch" technique for managing the wounds associated with open fractures.

\section{The "Bead Pouch" Technique}

This technique is applied after thorough wound ploration, irrigation and excision of devitalised tissug Skeletal stabilization is achieved, usually with externata fixation in the first instance, and the wounds then mataged as follows $(9,11)$ : one or more chains of aminoglycoside i pregnated PMMA beads are placed in the woune, and a drain is brought out through un-injurid skin. The wound area is covered with an adhesigec polyethylene wound drape (OpSite ${ }^{(i)}$ ) which g stapled to the wound edges, a second drape is the्]' placed over this to seal the staple holes. The dra is connected to a collecting bottle but is not placedo on suction; it is intended only for overflow fromo the pouch.

The wound is left for $48-72$ hours before it is re- $\overrightarrow{0}$ inspected in the operating theatre. At this stage the 3 wound may be suitable for delayed primary closure or closure by plastic surgical techniques. Alternatively aㅇ. further bead pouch may be made whilst the options for 3 closure are planned for later - the wound being re-inspected in a further 2-3 days.

\section{Case Reports}

The following two cases indicate how the bead pouch may be used to manage soft tissue wounds associated with open fractures:

A 14 year old girl sustained a severe open fracture of her right ankle in a road traffic accident. There was a large full thickness skin flap 을 over the medial malleolus, with extensive in $-\frac{D}{0}$ driving of mud and grass into the wound. Thorough wound toilet was carried out, and a N bead pouch fashioned over the malleolus, only partially covered by the flap of skin (Figs 1, 2 and 


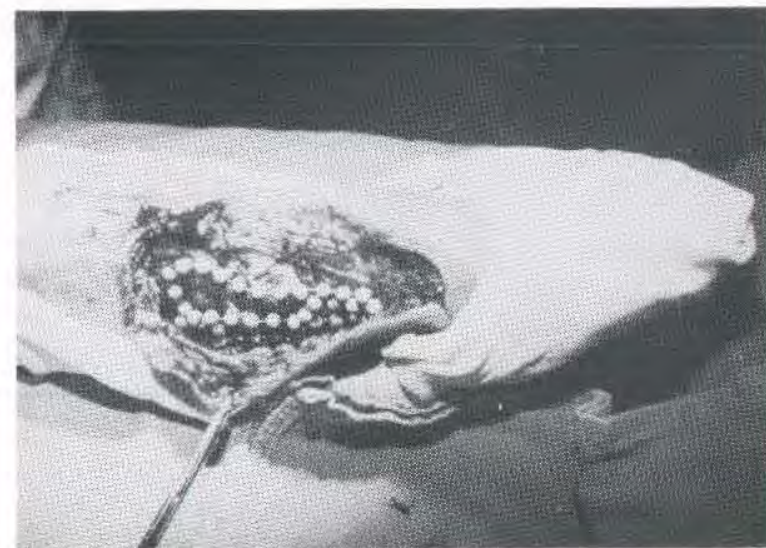

Fig 1. Extensive soft tissue avulsion over medial malleolus. Beads laid on wound.

\section{3). Intravenous antibiotics were commenced.}

The wound was reviewed in theatre at 48 hours, and assessed by the microsurgical team who agreed to perform a free-flap for coverage, as a planned procedure 7 days after the injury. A further antibiotic bead pouch was fashioned in the interim.

A 36 year old man was involved in a road traffic accident. He had severe facial injuries, a ruptured spleen and rupture of the left hemidiaphragm with traumatic herniation of abdominal contents into the left chest. His left femur was comminuted, with severe soft tissue wounds over both medial and lateral aspects of the thigh. Orthopaedic treatment of the thigh included thorough wound exploration and irrigation, then external fixation of the femur. The thigh wounds had tobramycinPMMA beads inserted (Fig 4), and bead pouches were fashioned. Intravenous antibiotics comprised penicillin, cefazolin and tobramycin.

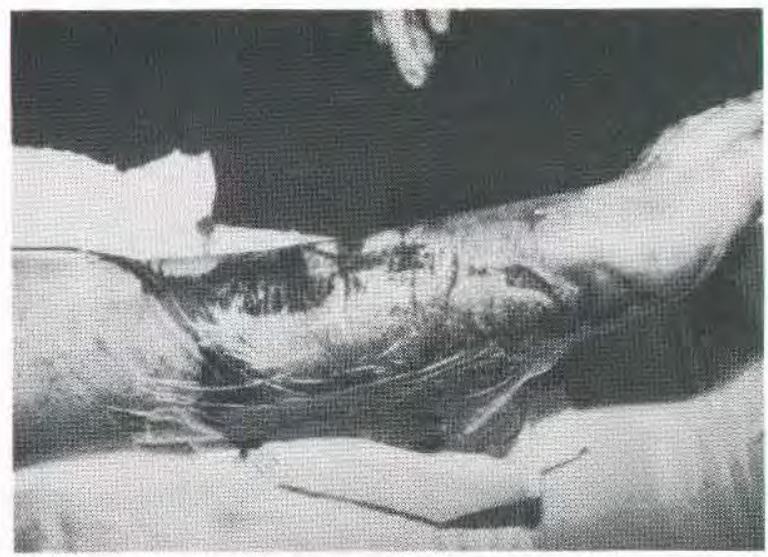

Fig 2. Wound covered with OpSite film.

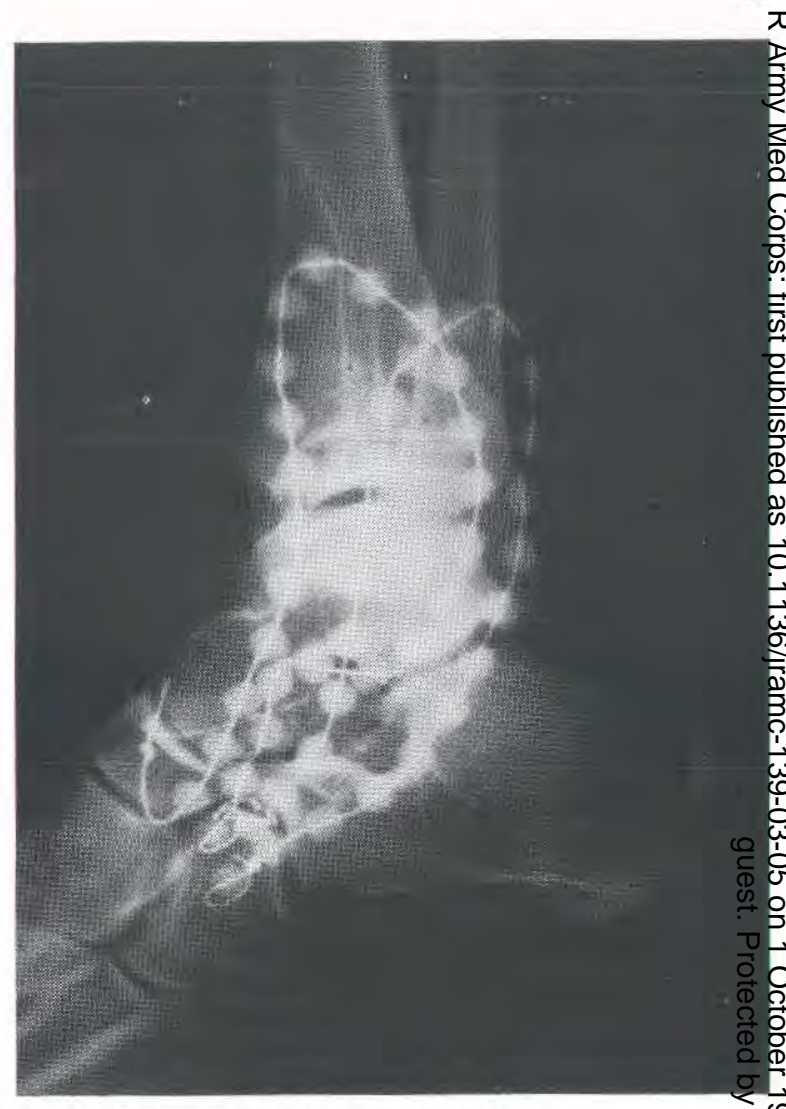

Fig 3. Radiograph of beads over ankle.

Subsequent treatment involved a re-examim tion of the wounds and change of beads at hours. The wounds were closed by delayed primary suture at 5 days, and after 10 days the femur was fixed with an intramedullary nail.

In each of these cases the orthopaedic problem was challenging, but stability was achieved; there were nog subsequent problems with bone or soft tissue infection The use of the bead pouch technique allowed manage ment of both bone and soft tissue to be planned and staged over a week, whilst maintaining an infection free environment and without compromising the bone by allowing it to dry out.

\section{Results - Infection Rates}

The results from the level 1 trauma centre in Louisville have shown the efficacy of antibiotic beads in oper. fractures (4). A total of 404 fractures were studied, all of which underwent acute irrigation and wound explora tion and excision of non-viable tissue. In 334 fractures systemic antibiotics were supplemented by antibioti $\$$ beads used locally in the wounds. The remainder wer? managed without beads, but in an otherwise identican manner, except that where closure could not be effected? a regimen of packing and serial dressings was used ir 


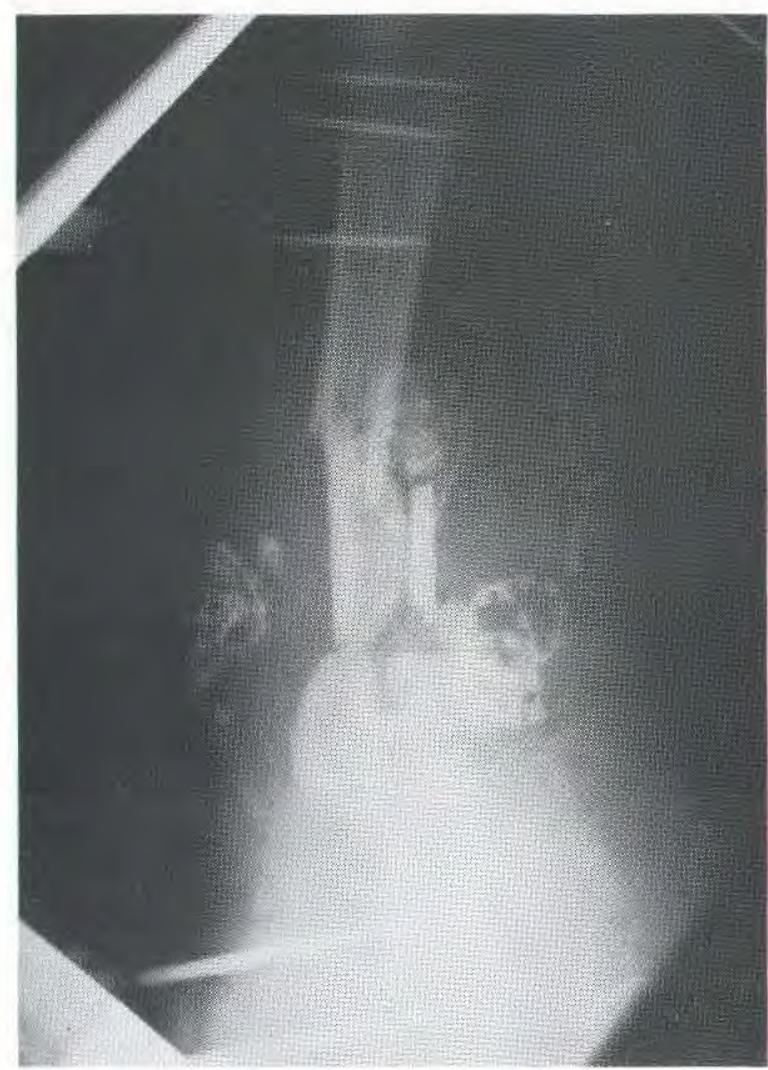

Fig 4. Radiograph of beads in wounds associated with comminuted open femoral fracture.

place of the bead pouch, until the wound could be closed or covered by plastic surgical techniques. The groups were matched for severity of fracture by Gustilo grading $(12,13)$ (defined in Table 1). Infection rates - both acute and chronic - were lower across all fracture grades in those managed with antibiotic beads; a summary of the results is given in Table 2.

The group at most risk of infection are those with the grade III fractures; it is for this group that the bead pouch technique is particularly useful (4). There was a highly significant reduction in acute and chronic infection in the grade III open fractures: $43.94 \%$ infection if beads not used, $8.7 \%$ if beads used $(p<0.001)$. The alarmingly high rate of infection in type III fractures managed without the use of antibiotic beads is borne out by other series: $44 \%$ in Gustilo's (12) and $41 \%$ in Chapman's (14). Approximately $50 \%$ of the type III fractures in the Louisville series were sub-type IIIB; these were equally distributed in the two treatment groups.

The open fracture of the tibia is a particular problem (15), and results for these grade II \& III tibial fractures, in which soft tissue cover is challenging, have shown benefit from the use of a bead pouch technique (16).
Table 1. Classification of Open Fractures - Based on Gustilo et al $(12,13)$

\begin{tabular}{|c|c|c|}
\hline Type & Fracture & Wound \\
\hline I & $\begin{array}{l}\text { Not high energy } \\
\text { pattern }\end{array}$ & wound less than $1 \mathrm{~cm}$, clean \\
\hline II & $\begin{array}{l}\text { Not high energy } \\
\text { pattern }\end{array}$ & $\begin{array}{l}\text { wound less than } 1 \mathrm{~cm} \text { long, } \\
\text { without extensive soft tissue } \\
\text { damage, flaps or avulsion }\end{array}$ \\
\hline IIIA & $\begin{array}{l}\text { Any high energy } \\
\text { pattern, (Regard- } \\
\text { less of size of } \\
\text { wound) }\end{array}$ & $\begin{array}{l}\text { Adequate soft tissue cover } \\
\text { despite extensive laceration or } \\
\text { flaps }\end{array}$ \\
\hline IIIB & & $\begin{array}{l}\text { Periosteal stripping, bony } \\
\text { exposure and massive } \\
\text { contamination (usually) }\end{array}$ \\
\hline IIIC & & $\begin{array}{l}\text { Associated arterial injury } \\
\text { requiring repair }\end{array}$ \\
\hline
\end{tabular}

These results for compare favourably with those reported in other large series $(12,17,18)$.

\section{Wound Closure}

It is well recognized that soft tissue coverage for the severe open fractures is of great importance in prevento ing infection $(12,13,19,20)$. Techniques for closure $\propto \bar{\Phi}$ cover include delayed primary suture for the grade III wounds, but plastic surgical techniques are employed foo the IIIB wounds $(21,22,23)$. Controversy continues ove the optimum timing of cover: some argue for immediat cover, using whatever plastic surgical technique is neo essary, including free-flaps (24). However, the genera consensus in many western European and Nor American centres is that cover should be achieved within a few days of injury $(20,25,26)$. This interval allows reexamination of the wound, as a planned procedure, to assess the adequacy of excision of non-viable tissue; the suitability of the wound for direct closure or plastic technique can be decided at these examinations.

If this planned delay between injury and coverage is to be accomplished without compromise, then the tissues must be kept free from infection, and most importantly the exposed bone must not be allowed to dry out in the interim (20). Here the bead pouch has obvious potential,

Table 2. Infection Rates in Open Fractures - Data from Louisville, Kentucky (Re-tabulated from reference 4)

\begin{tabular}{lccl}
\hline Type & $\begin{array}{l}\text { IV Antibiotics } \\
\text { Beads not used }\end{array}$ & $\begin{array}{l}\text { Beads plus IV } \\
\text { Antibiotics }\end{array}$ & $\begin{array}{l}\text { Signifi- } \\
\text { cance }\end{array}$ \\
\hline I & $2 / 23(8.7 \%)$ & $1 / 104(0.96 \%)$ & $\mathrm{p}<0.25$ \\
\hline II & $4 / 37(15.4 \%)$ & $4 / 127(3.2 \%)$ & $\mathrm{p}<0.05$ \\
\hline III & $9 / 21(43.9 \%)$ & $9 / 103(8.7 \%)$ & $\mathrm{p}<0.001$ \\
\hline
\end{tabular}

Overall $15 / 70(21.4 \%) \quad 14 / 334(4.2 \%) \quad \mathrm{p}<0.001$ 
maintaining a high local level of antibiotics in a moist environment. Alternative techniques such as moist dressings are more difficult to manage, requiring frequent changes if they are not to allow desiccation of the exposed bone.

\section{Potential Military Applications}

For wounds in which there is not excessive tissue loss, the principle of delayed primary suture (DPS) is well established and forms an essential part of military surgery $(27,28)$. In such wounds associated with a fracture the bead pouch technique may be complementary to DPS, providing a way to manage the wounds whilst closure is awaited.

The use of local antibiotics must not be regarded as a substitute for adequate wound surgery, the other major tenet of military surgery. It is emphasised that the wounds in the Kentucky series all underwent thorough exploration, irrigation and excision of devitalized tissue before the bead pouch was fashioned (4). However, as a method of managing wounds between primary wound surgery and eventual closure - be it by DPS or plastic surgery at a 4th or 5th line unit - the technique has much to offer.

It is in the management of severe open fractures that the bead pouch has greatest potential, as a means of combating infection, and preventing desiccation of the exposed bone whilst soft tissue cover is awaited. The constraints of the casualty evacuation chain may make a delay inevitable, and frequent dressing changes would be undesirable or impractical. If the wound has had adequate surgical exploration combined with skeletal stabilization (such as external fixation), and a bead pouch has been fashioned, then the fracture and would should need no further attention for up to 72 hours. This would allow evacuation rearwards to orthopaedic and plastic surgical expertise.

There may also be a role for this type of wound management when tendons have been repaired. In these circumstances it is important to prevent both infection and desiccation, but in many such cases it will be inadvisable to close the wound primarily. Here the antibiotic bead pouch is worth considering, as a temporizing measure.

\section{Further Research}

Research examining the benefits of antibiotic impregnated beads in acute trauma continues in North America. However, the commercially manufactured beads such as Septopal ${ }^{\circledR}$ (gentamicin-PMMA, by E Merck) are not licensed by the Food and Drugs Administration (FDA) for use in the United States. Research to demonstrate the efficacy and safety of aminoglycoside beads - in acute wound care and in the treatment of infected orthopaedic cases - is being conducted. In Louisville, Kentucky bead chains are made in the hospital pharmacy (10), and FDA approved trials are under way, aimed at gaining approval for the beads to be $D$ commercially available.

There has been concern over potential toxic levels of aminoglycoside which might be released when beads are $\Phi$ used in this manner. This has been researched and, despite very high local levels within the pouch, serum levels remain well below the toxic level $(9,10,29)$. Further of work has shown that even when these beads are implanted in a richly vascularized area - such as the max- $\stackrel{\mathcal{D}}{\stackrel{D}{+}}$ illofacial region - the serum levels of antibiotic remain negligible (30).

The United States Department of the Navy is sponsoring research into the use of antibiotic impregnated beads as the mainstay of antibiotic adminis- $ळ$ tration in open fractures. This is to be the subject of a $\vec{O}$ multi-centre trial, running over the next year, co-ordinated by the University of Louisville Fracture Service (Seligson, personal communication). This should show whether antibiotic beads alone can be used as prophylaxis in open fractures, thereby removing the logistic and nursing demands of regular parentral antibiotic ad- $\bar{\omega}$ ministration in the period between primary wound surgery and wound closure - particularly during patieat evacuation.

Recent research has examined different carrier media and a range of antibiotics, looking for the optimup combination for use in acute trauma (31). Plaster of Paris beads containing penicillin and flucloxacillin sho particular promise in vitro, with a pharmacokinetif profile which should lead to rapid high and sustaine $\overrightarrow{0}$ levels of antibiotic within a pouch. The choice of these antibiotics is in line with current policy as laid down Casualty Treatment Regimes (32), and with the bacteriological findings in wounds from the Gulf wa् (Cumberland and Green, unpublished communication). Work is planned to assess these beads further, including in vivo studies.

Antibiotic impregnated beads appear to be of benefit in acute musculo-skeletal trauma, and further results showing their efficacy in fracture management and prophylaxis of soft tissue infection are awaited with interest.

\section{Acknowledgments}

Research into the delivery of antibiotics by impregnated pellets has been approved by the Army Medical Services Research Executive. I am particularly obliged to them for their funding of a visit to Professor Seligson's unit in Kentucky, and I am most grateful to the Commandant, Royal Army Medical College and the Professor of Military Surgery for their support.

Research into antibiotics and carrier media was sup- $\rightarrow$ ported by a grant from the British Orthopaedic Association Wishbone Trust, for which I am grateful. This $N$ work has been carried out as part of the requirement for ${ }^{-}$ the degree of M Chir of the University of Cambridge. 


\section{REFERENCES}

1. KLEMM K. The treatment of chronic bone infection with gentamicin-PMMA beads and chains. Unfallchirurgie 1976; special symposium 1: 20-23.

2. JENNY G. Local antibiotic therapy using gentamicin-PMMA chains in post-traumatic bone infections. Short and long-term results. Reconstr Surg Traumatol 1988; 20: 36-46.

3. Klemm K. Infected non-unions. In: Green $S$, Sarmiento A. External fixation and functional bracing. Orthotext, London 1989.

4. Henry S L, Ostermann P A W, Seligson D. The prophylactic use of antibiotic impregnated beads in open fractures. J Trauma 1990; 30: 1231-8.

5. Seligson D, Henry $S$ L. Treatment of compound fractures. Am J Surg 1991; 161: 693-701.

6. Buchiolz $\mathrm{H}$ W, Engelbrecht $\mathbf{h}$. Uber die Depotwirkung einiger Antibiotica bei Vermischung mit dem Kunstharz Palacos. Chirug 1970; 41: 511 5.

7. Spence R A J, Anderson J R, Parks T G. The use of Gentamicin-PMMA chains in colorectal surgery. Br J Clin Pract 1984; 38: 252-4.

8. GRIEBEN A. Results of Septopal (R) in more than 1500 cases of bone and soft tissue infection. J Bone Joint Surg 1980; 62B: 275-279.

9. Eckman J B, Henry S L, Mangino P, Seligson D. Wound and serum levels of tobramycin with the prophylactic use of tobramycin-impregnated polymethylmethacrylate beads in compound fractures. Clin Orthop 1988; 237: 213-215.

10. Henry S L, Seligson D, Mangino P, Popham G J. Antibiotic-impregnated beads: Part I: Bead implantation versus systemic therapy. Orthop Rev 1991; 20: 242-247.

11. Selison D, Banis J, Matheny L. Tiba terrible. In: Coombs R, Green S, Sarmiento A. External fixation and functional bracing. Orthotext, London 1989.

12. Gustilo R B, Anderson J T. Prevention of infection in the treatment of 1025 open fractures of long bones. J Bone Joint Surg 1976; 58A: 453-8.

13. Gustilo R B, Mendoza R M, Williams D N. Problems in the management of Type III (severe) open fractures: a new classification of Type III open fractures. J Trauma 1984; 24: 742-6.

14. Chapman M W, Mahoney $M$. The role of early internal fixation in the management of open fractures. Clin Orthop 1979; 138: 120-131.

15. Gotzen L, HAAS N. The operative treatment of tibial shaft fractures with soft tissue injuries. In: Tscherne H \& Gotzen L, Fractures with soft tissue injuries. Springer Verlag, Berlin 1984.
16. Ostermann $\mathrm{P}$ A $\mathrm{W}$, Henry $\mathrm{S}$ L, Seligson $\mathrm{D}$. Behandlung von zweit- und drittgradig komplizierten Tibiaschaftfrakturen mit der PMMA-Kettentaschen-Technik. Unfallchirugie 1989; 92: 523-530.

17. Cierny G, Byrd H S, Jones R E. Primary versus delayed soft tissue coverage for severe open tibial fractures. A comparison of results. Clin Orthop 1983; 178: 54-63.

18. Caudle R J, Stern P J. Severe open fractures of the tibia. J Bone Joint Surg 1987; 69A: 801-7.

19. TSCHERNE H. Management of open fractures. In: Tscherne H \& Gotzen L, Fractures with soft tissue injuries, Springer Verlag, Berlin 1984.

20. Gustilo R B, Merkow R L, Templeman D. Current concepts review - The management of open fractures. J Bone Joint Surg 1990; 72A: 299-304.

21. PONTEN B. The fasciocutaneous flap: its use in soft tissue defects of the lower leg. Br J Plast Surg 1981; 34: $215-220$.

22. WRIGHT J K, WATKINS R P. Use of the soleus muscle flap to cover part of the distal tibia. Plast Reconstr Surg 1981; 12: 957-958.

23. Weiland A J, Moore J R, Hotchkiss R N. Soft tissue procedures for reconstruction of tibial shaft fractures. Clin Orthop 1983; 178: 42-53.

24. Godina M. Early microsurgical reconstruction of complex trauma of the extremities. Plast Reconst $F^{+}$ Surg 1986; 78: 285-292.

25. Godfrey A M. Lower limb trauma: primary treat ment and reconstruction. Ann $R$ Coll Surg Engg 1989; 71: 200-2.

26. Keating J, Court-Brown C M, McQueen M Mำ Christie J, Quaba A. Fasciocutaneous flaps in the management of open tibial fractures. Presented at 8 British Trauma Society Meeting 1992, Edinburgh.

27. Cleveland M, Grove J A. Delayed primary closure of wounds with compound fractures. J Bone Join $\overline{2}$ Surg 1945; 27: 452-456.

28. Kirby N G, Blackburn G (Eds). Field Surgery Pocket Book. London, HMSO, 1981.

29. WAHLIG $\mathrm{H}$, Dingeldein $\mathrm{E}$, et al. The release of gentamicin from polymethylmethacrylate beads. $J$ Bone Joint Surg 1978; 60B: 270-5.

30. Alpert B, Colosi T, et al. The in vivo behaviour of gentamicin-PMMA beads in the maxillofacial region. J Oral Maxillofac Surg 1989; 47: 46-9.

31. Bowyer $G \mathrm{~W}$, Cumberland N. Antibiotic release from impregnated pellets and beads. $J$ Trauma (in press).

32. Army Medical Services in the Field Aide Memoire. Pamphlet No 1 Casualty Treatment Regimes, 1986. Army Code 62264. (Restricted) 